Yuxiang Ye

Jan Bogaert

\title{
Cell therapy in myocardial infarction: emphasis on the role of MRI
}

Published online: 21 February 2008

(C) European Society of Radiology 2007

The layout of Table 2 was incorrect. The correct version is given here.

\footnotetext{
The online version of the original article can be found at http://dx.doi.org/10.1007/ s00330-007-0777-9.

Y. Ye $\cdot$ J. Bogaert $(\bowtie)$

Department of Radiology,

University Hospital K.U.L.,

Herestraat 49,

3000 Leuven, Belgium

e-mail: jan.bogaert@uz.kuleuven.ac.be
} 
Table 2 Comprehensive use of cardiac MRI-MRS

Cine MRI using SSFP technique

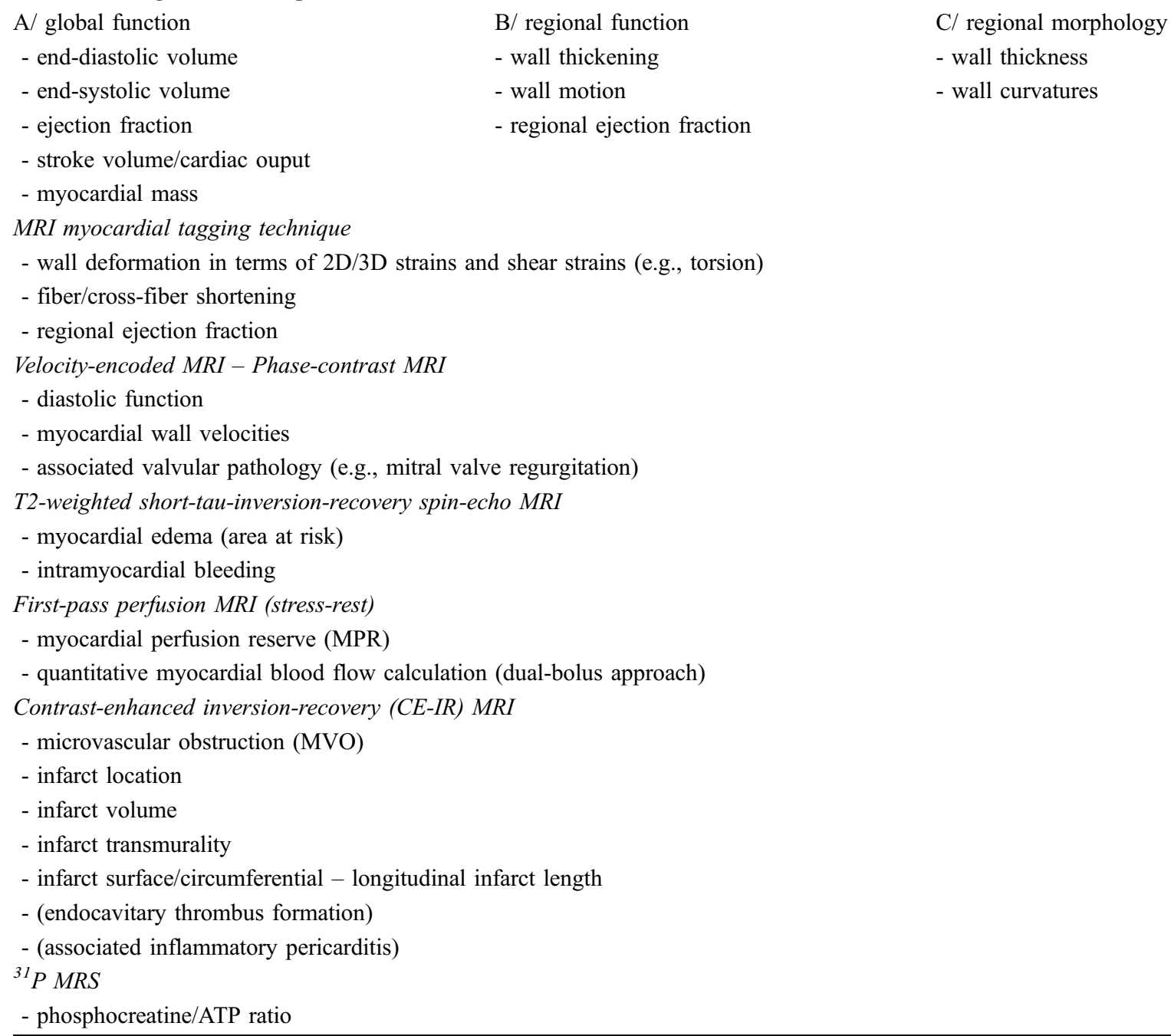

$\mathrm{B} /$ regional function

- wall thickening

- end-diastolic volume

- end-systolic volume

- ejection fraction

- stroke volume/cardiac ouput

- myocardial mass

MRI myocardial tagging technique

- wall deformation in terms of 2D/3D strains and shear strains (e.g., torsion)

- fiber/cross-fiber shortening

- regional ejection fraction

Velocity-encoded MRI - Phase-contrast MRI

- diastolic function

- myocardial wall velocities

- associated valvular pathology (e.g., mitral valve regurgitation)

T2-weighted short-tau-inversion-recovery spin-echo MRI

- myocardial edema (area at risk)

- intramyocardial bleeding

First-pass perfusion MRI (stress-rest)

- myocardial perfusion reserve (MPR)

- quantitative myocardial blood flow calculation (dual-bolus approach)

Contrast-enhanced inversion-recovery (CE-IR) MRI

- microvascular obstruction (MVO)

- infarct location

- infarct volume

- infarct transmurality

- infarct surface/circumferential - longitudinal infarct length

- (endocavitary thrombus formation)

- (associated inflammatory pericarditis)

${ }^{31} P M R S$

- phosphocreatine/ATP ratio

C/ regional morphology

- wall thickness

- wall curvatures 